\title{
PET ENGLISH: IMPLEMENTAÇÃO DO PROCESSO DE ENSINO E APRENDIZAGEM EM LÍNGUAS ESTRANGEIRAS NO GRUPO PET DE ENGENHARIA CIVIL DO CEFET-MG
}

DOI: $10.37702 / 2175-957 X . C O B E N G E .2021 .3484$

Fernanda Brandão Gastaldi Mattos - fernandabrandao1998@gmail.com

Centro Federal de Educação Tecnológica de Minas Gerais

Rua Engenheiro Carlos Mata Machado 274

35790-000 - Curvelo - SP

Gerfenson Barbosa Ribeiro - gerfenson19@gmail.com

Centro Federal de Educação Tecnológica de Minas Gerais

Rua Joaquim Murtinho 416

32185-270 - Contagem - MG

Gabriela Santos de Andrade - gabrielaandrade74@hotmail.com

CEFET

Avenida Dom Pedro II 699

39670-000 - Curvelo - MG

Patrícia Bhering Fialho - patriciabhering@bol.com.br

Centro Federal de Educação Tecnológica de Minas Gerais

Rua Santa Rita 900

35790-000 - Curvelo - MG

Ana Cecília Estevão - anacestevao@yahoo.com.br

CEFETMG

Rua juvenal Pereira Soares 78

35790-000 - Curvelo - MG

Resumo: Aprender um idioma estrangeiro é um passo muito importante para abrir um leque de oportunidades, sejam elas na vida pessoal, profissional ou acadêmica. É imprescindível também ponderar quais são os seus objetivos e tê-los bem claros para que não se perca ou desista no meio do caminho ao aprender essa nova língua, pois se trata de uma jornada longa. A partir disso, foi realizada uma pesquisa para constatar o conhecimento e o nível dos alunos na língua inglesa; 
como resultado, foi obtido nenhuma proficiência em línguas estrangeiras e nível muito básico em inglês. Diante disso, o programa de educação tutorial (PET) de Engenharia Civil do CEFET-MG, Campus Curvelo, realizou um uma atividade de ensino aplicada aos integrantes do grupo, intitulada PET English, com o objetivo de ampliar a produção científica do grupo a língua inglesa e ter contato com maior gama de referências internacionais. Ao final do curso realizou-se um levantamento com os participantes, onde foi possível constatar que os mesmos obtiveram uma boa experiência com o curso, e que possivelmente dariam progresso aos estudos.

Palavras-chave: Inglês. Ensino. Aprendizado. Duolingo. 


\section{PET ENGLISH: IMPLEMENTAÇÃO DO PROCESSO DE ENSINO E APRENDIZAGEM EM LÍNGUAS ESTRANGEIRAS NO GRUPO PET DE ENGENHARIA CIVIL DO CEFET-MG.}

\section{INTRODUÇÃO}

A linguagem é um meio de diálogo e apresentação, praticada por variados idiomas, que se diferenciam por meio de regras gramaticais e se estabelecem de acordo com 0 ambiente (KO Y, 2010; LEMHOFER K, 2010). Entende-se que o ensino de uma língua estrangeira deve-se considerar os vieses interculturais, visando preservar as identidades culturais, com o objetivo de propiciar a troca de experiências e o enriquecimento mútuo (FERNANDES; EIRÓ, 2013, p. 108).

Para Soares e Lima (2019) no âmbito de ensino-aprendizagem, a tecnologia comprovou que a interatividade permite o maior e o mais rápido acesso à informação. Datashow, tablets, lousas digitais, jogos, redes sociais, vídeos e sites educativos se tornaram aliados de docentes e alunos. Com a popularização e crescimento da utilização dos smartphones, professores e alunos têm tido acesso a aplicativos que, a título de exemplo, possibilitam o ensino-aprendizagem de línguas estrangeiras, como é o caso do Duolingo.

No contexto atual, em que a humanidade está cada vez mais dependente dos mecanismos tecnológicos existentes, o mundo encontra-se mais globalizado do que em outros momentos. A partir da inserção da tecnologia obtivemos mais multiplicidade na troca de mensagens, e, atualmente, estamos experienciando um avanço tecnológico tanto na área informativa quanto na comunicativa, que distribui, além de conhecimento, entretenimento para seus usuários. A educação e o processo de ensino necessitam incluir essas transformações em seu contexto escolar. Com isso, precisamos trabalhar de forma integrada ao processo pedagógico, pois essa é uma forma de aproximar a geração que está nos bancos escolares (SILVA et al., 2020).

Segundo o estudo desenvolvido pelo Instituto de Pesquisas Plano CDE (2015), os docentes de língua inglesa acreditam que a matéria exige mais atividades com temáticas que envolvem dinâmicas divertidas e participação dos alunos, sendo os recursos tecnológicos indispensáveis para atingir esse objetivo; o que leva a uma reflexão sobre como se torna cada vez mais importante a inclusão eficiente das novas tecnologias nas aulas de inglês (BARROS, ABRANCHES,2016).

A geração de aplicativos educacionais vem crescendo num formato gradativo, tanto na forma gratuita como nas pagas, e a aprendizagem não formal de línguas vem sendo uma tendência nesse sentido, uma vez que vem apresentando uma oferta vasta de aplicativos nesta área. Diante desse contexto, o aplicativo utilizado para o desenvolvimento do curso foi o Duolingo, que é a maior plataforma online de aprendizado de idiomas do mundo (SANTANA et al.,2018).

O objetivo deste trabalho, é apresentar os resultados do processo de implementação e aplicação de metodologias de ensino de idiomas dentro de grupos PET de Engenharia Civil do CEFET-MG, Campus Curvelo, com o intuito de estimular o desenvolvimento profissional e ter uma formação mais completa. 


\section{REFERENCIAL TEÓRICO}

\section{$2.1 \quad$ Língua Inglesa}

Segundo a Cultura Inglesa (2020), a Língua Inglesa é o idioma mais falado no planeta, além de ser utilizado largamente pela comunidade internacional para negociações diplomáticas e cooperação internacional, com isso é considerado um dos idiomas mais importantes do mundo.

Várias universidades em países não-anglófonos ao redor do mundo estão investindo em iniciativas de internacionalização para que possam possuir pelo menos um curso ministrado no idioma inglês. Em resultado disso, essas universidades começaram a exigir aos estudantes, proficiência no idioma para entrada ou para colação de grau. Exemplo disso, são os grandes grupos de Universidades Francesas como a PARISTECH, que exige que o graduando tenha pelo menos um nível intermediário (B2) na data da sua colação de grau.

Segundo Busuu (2021) e Go Natural English (2021), o idioma inglês é um dos idiomas mais fáceis de se aprender. Visto a baixa complexidade da sua gramática e a alta gama de conteúdo disponível online de maneira gratuita e acessível. É importante ressaltar também que o tempo demandado para atingir a fluência nesse idioma, cerca de 1200 horas, é relativamente baixo, se comparado a outros idiomas de origem asiática, como por exemplo o chinês (madarim), que demanda aproximadamente 2200 horas de estudo.

\subsection{Ensino e Aprendizagem da Língua Inglesa}

Em um mundo cada vez mais globalizado, várias ferramentas de aprendizagem foram e são desenvolvidas em curtos espaços de tempo, dando aos estudantes a possibilidade de aprender de uma maneira sistemática e assertiva, de acordo com o seu tempo disponível e seu nível de motivação, sem estar limitado a somente fazer aulas em escolas de idiomas ou ter que viajar a outro país para conseguir fazer uma imersão no idioma e na cultura estudada.

Cada indivíduo tem uma especificidade no aprendizado de línguas, demandando a utilização de diferentes métodos de aprendizagem de pessoa para pessoa. Alguns podem preferir ter aulas em uma escola de idiomas visto que sentem uma maior necessidade de acompanhamento, e outros podem preferir ser autodidatas seguindo seus estudos de um modo mais autônomo. LIMA (2004) especifica que não existem métodos milagrosos, mas sim planos de estudos muito bem desenvolvidos e adaptados para a realidade de cada estudante.

Segundo Fragozo (2018), o aprendizado de idiomas demanda a necessidade de traçar metas para que o estudante consiga visualizar onde quer chegar, fazendo um plano de estudos direcionado para o que deseja almejar, considerando que quando partir do nível básico não estipular prazos até conseguir alcançar um nível satisfatório no idioma, para não causar frustrações e se manter motivado até o final.

É importante ressaltar que a Língua Inglesa é um idioma de nível de utilização mundial, ressaltando ainda mais a importância do seu aprendizado, que possibilita a abertura de portas dentro e fora do Brasil, em resultado das políticas de internacionalização de empresas e de instituições de ensino a fim de criar uma cooperação internacional sólida.

\subsection{Duolingo}

O Duolingo é uma plataforma de aprendizagem de idiomas que tem como objetivo ensinar de forma gratuita, divertida e acessível a todos. Por se tratar de uma plataforma gamificada, ou seja, desenvolvida para funcionar como um jogo, cada lição é uma fase e 
ao se concluir uma lição, outra é desbloqueada, levando assim, ao progresso da aprendizagem (DUOLINGO, 2021).

Segundo o Duolingo (2021), todos os cursos de idiomas são exibidos em forma de uma árvore de aprendizado com várias unidades, que são os círculos coloridos, onde cada unidade é dividida em 5 níveis que são compostos por lições individuais. Ao realizar cada lição e completar um nível você ganha uma coroa, como em cada unidade tem 5 níveis, ao se completar a unidade você ganha cinco coroas, como mostra a Figura 1.

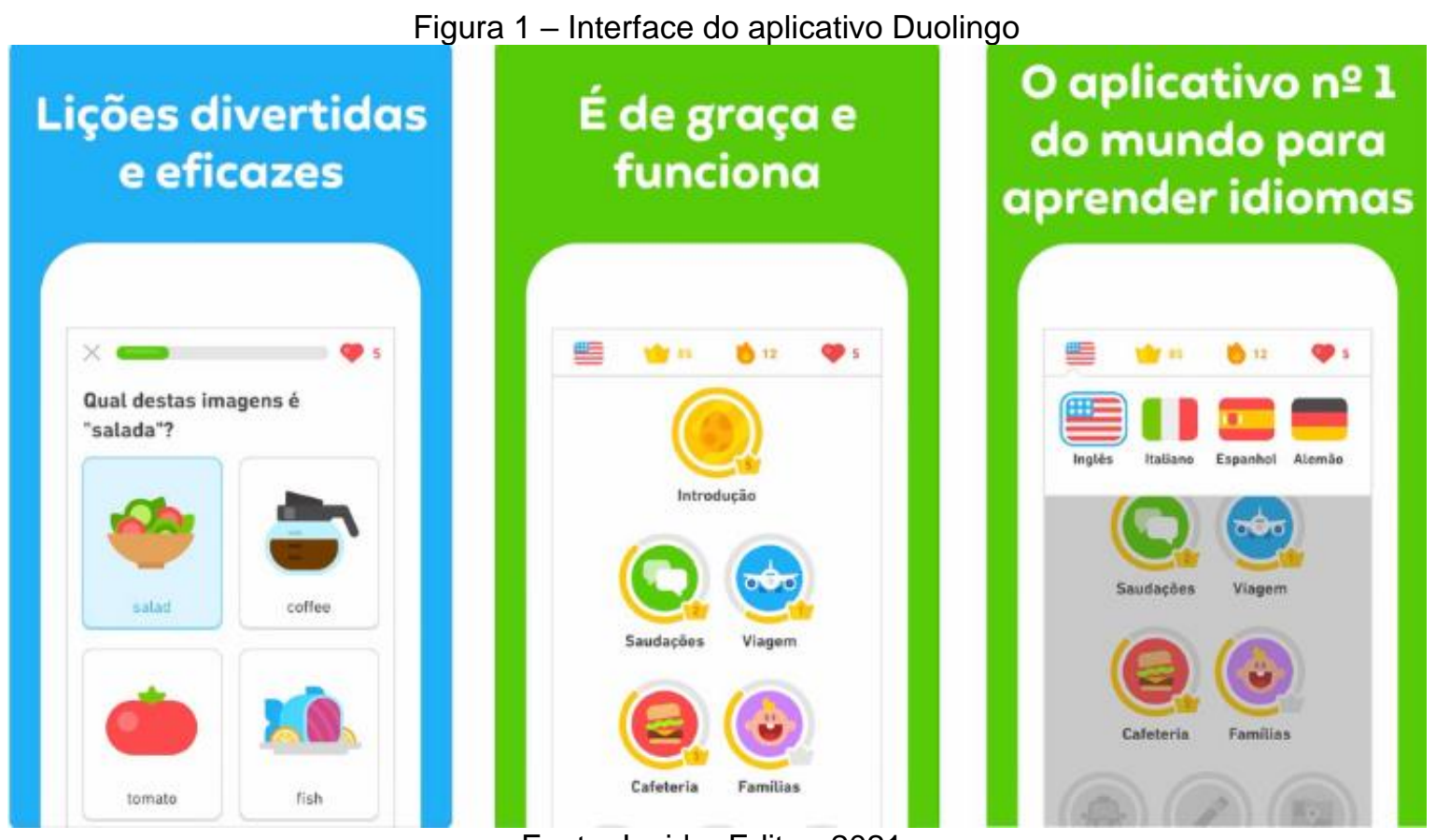

Fonte: Insider Editor, 2021

Apesar de funcionar como um jogo, o Duolingo é baseado em um método cientificamente comprovado que propicia uma capacidade de armazenamento de memória a longo prazo. $O$ aprendizado concentra-se em desenvolver o vocabulário e a gramática essencial para alcançar os objetivos da vida real, como fazer pedidos e se apresentar, por meio de práticas variadas de leituras, escrita, escuta e fala (DUOLINGO, 2021).

Existe, também, um espaço exclusivo para educadores na plataforma, que se chama Duolingo para Escolas, que permite aos professores criarem uma sala de aula, onde será possível acessar e acompanhar o desempenho de cada aluno individualmente, além de desenvolver atividades especialmente para a sala (DUOLINGO, 2021).

\section{METODOLOGIA}

Inicialmente, aplicou-se um questionário aos membros do grupo com o intuito de analisar se os mesmos tinham conhecimento em algum idioma estrangeiro; e qual era 0 nível do conhecimento em língua inglesa.

O minicurso PET English foi ministrado por um aluno petiano, exclusivamente, para os 12 (doze) integrantes do grupo PET de Engenharia Civil com o objetivo de criar uma base de conhecimento no idioma, na qual os participantes eram incentivados a criar suas próprias rotinas de estudos baseados em vários métodos apresentados em aula, além de dar a possibilidade de praticar nos encontros semanais, propiciando que desenvolvessem e adaptarem o aprendizado de idiomas a sua rotina de modo que ficasse mais à vontade possível. 
O minicurso foi realizado durante os meses de abril, maio e junho, onde foi estruturado em três pilares. O primeiro foi "Exposição", na qual os participantes recebiam tarefas diárias de aproximadamente 15 minutos a serem cumpridas na plataforma Duolingo para a aquisição de vocabulário e escrita; o segundo pilar foi a "Prática", realizada em quinze encontros semanais através de videoconferências pela plataforma Zoom onde o principal foco era estimular os participantes a praticar o que foi absorvido anteriormente e fixando os conteúdos. Já o último pilar, "Experimentação", foi fundamental na medição do progresso que os estudantes tiveram desde a primeira aula até o último encontro, possibilitando-os mensurar o desempenho do curso.

O primeiro encontro foi selecionado para explicar a importância do aprendizado da língua estrangeira e, especificamente, da importância da língua inglesa, além da explicação de como seria realizado e funcionaria o curso para os integrantes. Os demais encontros foram destinados ao ensino, aprendizagem e prática dos conhecimentos obtidos na plataforma em formas de diálogos juntos com os demais participantes. As atividades no Duolingo nas quais tinham temas de assuntos do cotidiano, como apresentação pessoal, atividades diárias e solicitar informações.

Além das atividades realizadas no Duolingo e do relatório gerado pela plataforma através do Duolingo Escola em relação ao desenvolvimento do aluno, no último encontro, também, foi aplicado um teste de proficiência a todos os participantes, elaborado de acordo com o conteúdo ministrado, a fim de verificar o desempenho individual de cada participante.

Por fim, foi aplicado um questionário, por meio da plataforma Google Forms, para que os participantes avaliassem o curso através de perguntas objetivas.

\section{RESULTADOS}

Os resultados do questionário, para análise do conhecimento e nível dos alunos sobre aprendizagem em línguas estrangeiras, aplicado inicialmente estão apresentados na Figura 2.

Figura 2 - Gráficos sobre o conhecimento e o nível dos alunos sobre o idioma.

(a) Conhecimento de algum idioma estrangeiro: (b) Nível do conhecimento em inglês.

(a) Você ja tem proficiencia em algum outro idioma, além do portugues?

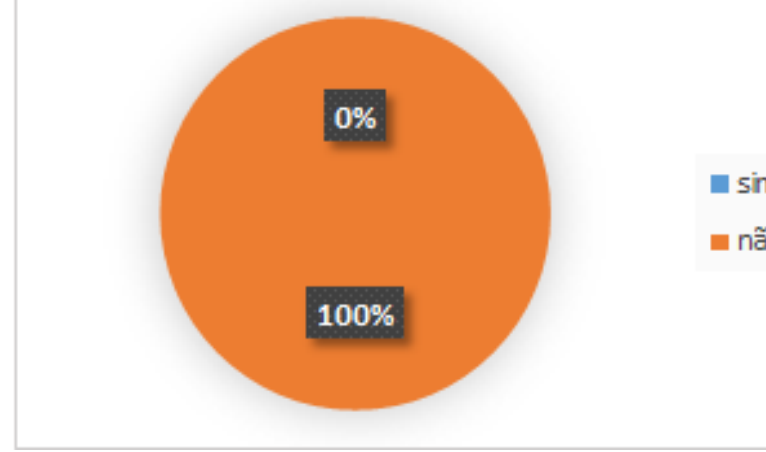

(b) Se fosse para você autoavaliar seu conhecimento em inglês, qual seria?

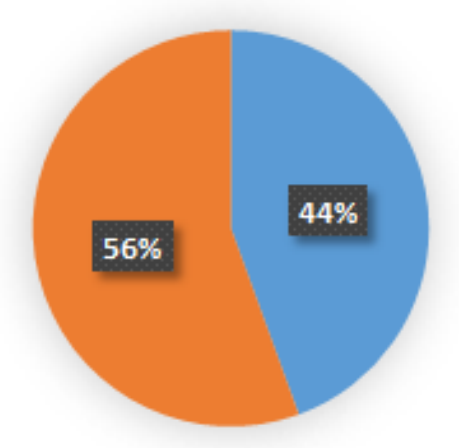

- Muito básico - Básico

n Pré-Inter mediário

n Inter mediário

- Avançado

Fonte - Autores, 2021

Conforme o gráfico apresentado acima (figura 2), é possível observar que a maioria dos alunos não tinham proficiência em outro idioma, mas em sua maioria possuíam pelo menos um nível muito básico ou básico em inglês. Diante disso, foi proposto a realização de atividades de fundação no idioma dentro da plataforma do Duolingo, como demonstrado na Figura 3, para uma aprendizagem mais eficaz. 
Figura 3 - Cronograma de atividades do Duolingo.

\begin{tabular}{|c|c|c|c|}
\hline \multicolumn{4}{|c|}{ Abril } \\
\hline Atividade & $\mathrm{N}^{\circ}$ de lições & Data de inicio & Data final \\
\hline Introdução & 3 & 16 de abr de $202000: 00$ & 16 de abr de $202023: 00$ \\
\hline Saudações & 3 & 17 de abr de $202000: 00$ & 17 de abr de $202023: 00$ \\
\hline Viagem & 3 & 20 de abr de $202000: 00$ & 20 de abr de $202023: 00$ \\
\hline Cafeteria & 4 & 21 de abr de $202000: 00$ & 21 de abr de $202023: 00$ \\
\hline Familias & 4 & 22 de abr de $202000: 00$ & 22 de abr de $202023: 00$ \\
\hline Loja & 4 & 23 de abr de $202000: 00$ & 23 de abr de $202023: 00$ \\
\hline Estudos & 4 & 24 de abr de $202000: 00$ & 24 de abr de $202023: 00$ \\
\hline Ocupaçōes & 3 & 27 de abr de $202000: 00$ & 27 de abr de $202023: 00$ \\
\hline Encontros & 3 & 28 de abr de $202000: 00$ & 28 de abr de $202023: 00$ \\
\hline Rotinas & 4 & 29 de abr de $202000: 00$ & 29 de abr de $202023: 00$ \\
\hline Emoçōes & 3 & 30 de abr de $202000: 00$ & 30 de abr de $202023: 00$ \\
\hline
\end{tabular}

\begin{tabular}{|c|c|c|c|}
\hline \multicolumn{4}{|c|}{ Maio: } \\
\hline Atividade & $\mathbf{N}^{\circ}$ de lições & Data de inicio & Data final \\
\hline Comida & 4 & 1 de mai de $202000: 00$ & 1 de mai de $202023: 00$ \\
\hline Horas & 4 & 4 de mai de $202000: 00$ & 4 de mai de $202023: 00$ \\
\hline Parentes & 4 & 5 de mai de $202000: 00$ & 5 de mai de $202023: 00$ \\
\hline Em casa & 4 & 6 de mai de $202000: 00$ & 6 de mai de $202023: 00$ \\
\hline Compras & 4 & 7 de mai de $202000: 00$ & 7 de mai de $202023: 00$ \\
\hline Atividades & 4 & 8 de mai de $202000: 00$ & 8 de mai de $202023: 00$ \\
\hline Atividades $\mathbf{2}$ & 4 & 11 de mai de $202000: 00$ & 11 de mai de $202023: 00$ \\
\hline Encontros 2 & 4 & 12 de mai de $202000: 00$ & 12 de mai de $202023: 00$ \\
\hline Compras 2 & 4 & 13 de mai de $202000: 00$ & 13 de mai de $202023: 00$ \\
\hline Clima & 4 & 14 de mai de $202000: 00$ & 14 de mai de $202023: 00$ \\
\hline Aventuras & 4 & 15 de mai de $202000: 00$ & 15 de mai de $202023: 00$ \\
\hline Restaurante & 4 & 18 de mai de $202000: 00$ & 18 de mai de $202023: 00$ \\
\hline Pessoas & 4 & 19 de mai de $202000: 00$ & 19 de mai de $202023: 00$ \\
\hline Animais & 4 & 20 de mai de $202000: 00$ & 20 de maide $202023: 00$ \\
\hline Descrição & 4 & 21 de mai de $202000: 00$ & 21 de mai de $202023: 00$ \\
\hline Direçōes & 4 & 22 de mai de $202000: 00$ & 22 de mai de $202023: 00$ \\
\hline Gostos & 4 & 25 de mai de $202000: 00$ & 25 de mai de $202023: 00$ \\
\hline Escola & 4 & 26 de mai de $202000: 00$ & 26 de mai de $202023: 00$ \\
\hline Planos & 4 & 27 de mai de $202000: 00$ & 27 de mai de $202023: 00$ \\
\hline Histórias & 4 & 28 de mai de $202000: 00$ & 28 de mai de $202023: 00$ \\
\hline Trabalho & 4 & 29 de mai de $202000: 00$ & 29 de mai de $202023: 00$ \\
\hline
\end{tabular}

Fonte - Autores, 2021.

No cronograma de atividades apresentado verificou-se que os temas discutidos buscavam relacionar atividades exercidas no dia-a-dia com as que são de grande importância para comunicação, como: saudações, trabalho e comida.

Ao final do curso, foi gerado um relatório das atividades realizadas dentro da plataforma separadamente por cada integrante (figura 4) com o objetivo de mostrar 0 esforço e dedicação de cada membro diante das tarefas ofertadas. 
Figura 4 - Relatório das atividades realizadas por cada integrante na plataforma.

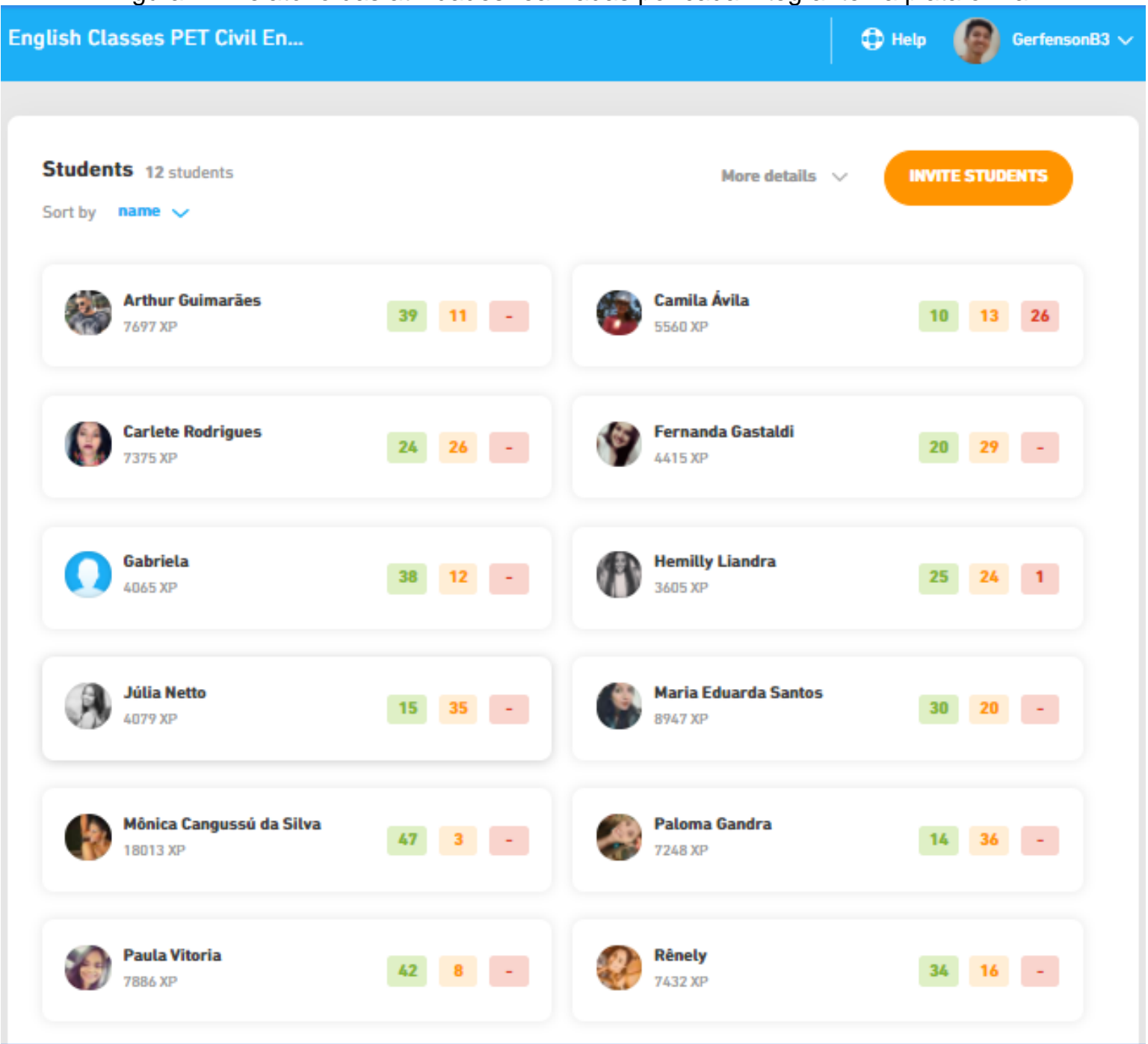

$$
\text { Fonte - Autores, } 2021 .
$$

No relatório descrito na figura 4, verifica-se a classificação das atividades realizadas; em verde, temos o número de atividades realizadas pelo aluno dentro do tempo estipulado, em amarelo, as atividades realizadas pelos alunos com atraso, e em vermelho, as lições não realizadas pelos alunos. Diante disso, podemos dizer que a maioria dos alunos realizaram as atividades ministradas.

Com o objetivo de mensurar o desempenho dos estudantes no curso, foi aplicado um teste de proficiência de múltipla escolha, no qual foi possível verificar se a maioria dos participantes tiveram um resultado satisfatório, como mostra a figura 5. 
Figura 5 - Gráficos do teste de proficiência a todos os participantes. (1) Pergunta número um do teste; (2) Pergunta número dois do teste; (3) Pergunta número três do teste; (4) Pergunta número quatro do teste; (5)

Pergunta número cinco do teste; (6) Pergunta número seis do teste.

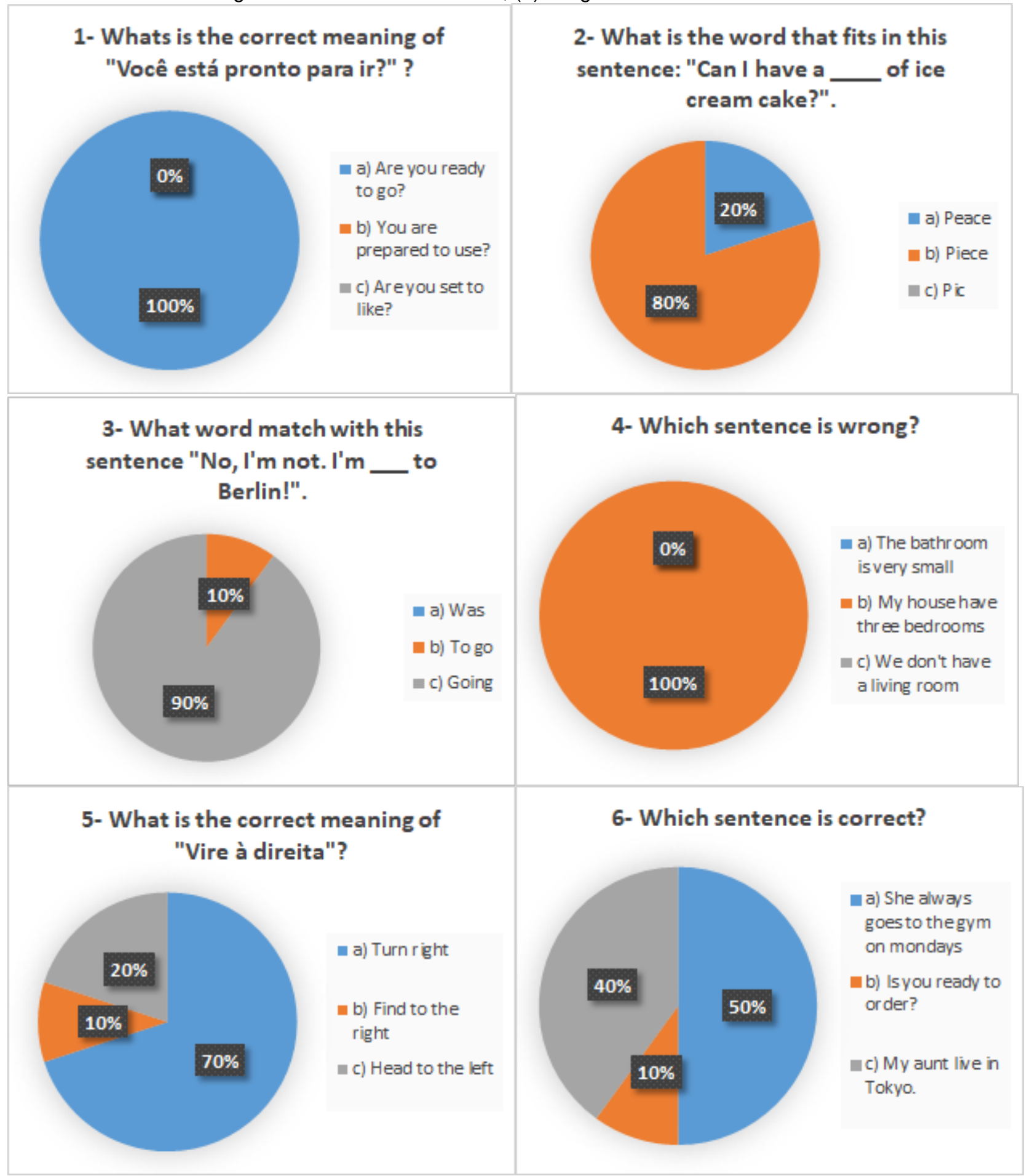

Fonte - Autores, 2021

Por meio dos dados apresentados, o curso obteve resultado satisfatório, uma vez que grande parte dos alunos (85\%) acertaram a maioria (95\%) das questões propostas no teste.

Por fim, foi aplicado um questionário aos participantes, para que pudessem avaliar a sua experiência com o minicurso. Os resultados dos questionários aplicados sobre 0 minicurso do PET English estão representados na Figura 6. 
Figura 6 - Gráficos sobre a avaliação do curso. (a) Opinião sobre a qualidade das aulas; (b) Opinião a respeito da qualidade do curso; (c) Considerações sobre a aprendizagem; (d) Considerações sobre o desempenho do professor.

(a) A respeito de como está sendo conduzido os encontros de conversação, escolha uma opção:

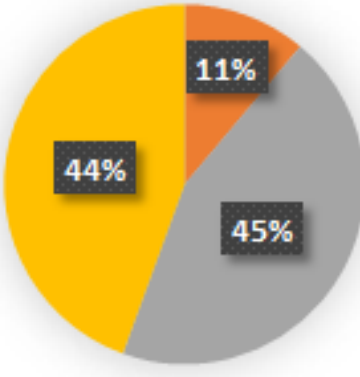

(c) Você acha que está conseguindo aprender com a atividade proposta?

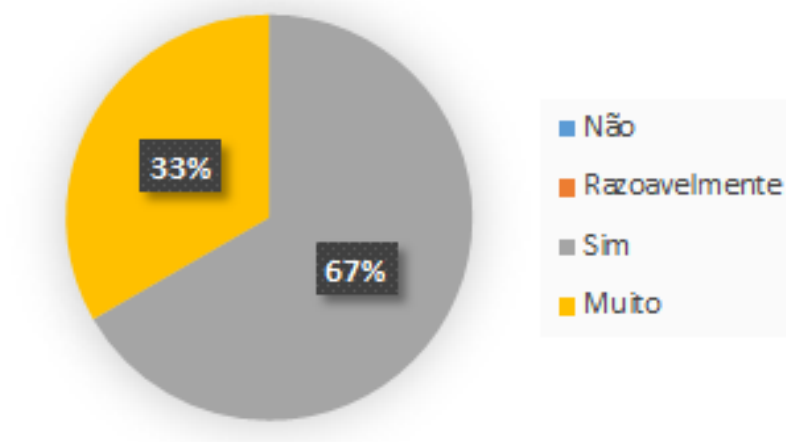

(b) o que vc está achando do curso?

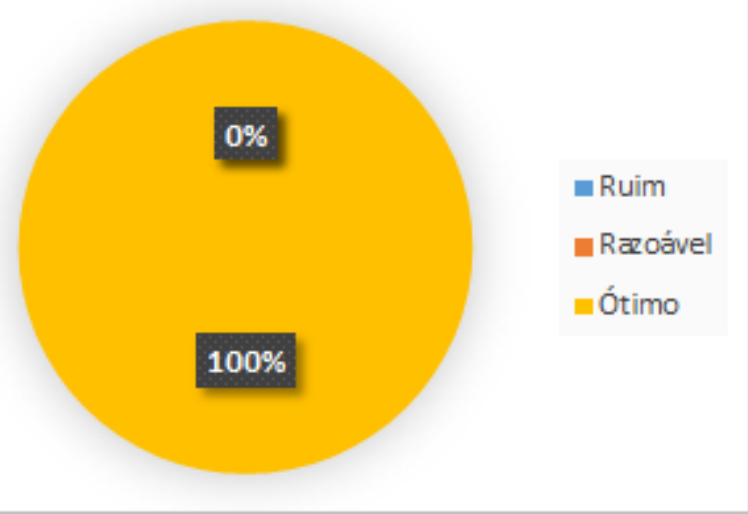

Fonte - Autores, 2021

Como foi possível constatar com as respostas dos formulários acima, o curso conseguiu atender de modo efetivo a aprendizagem dos participantes, visto que a principal preocupação era conseguir que todos fossem o mais produtivo possível, a fim de tirarem o máximo de proveito do curso.

\section{CONSIDERAÇÕES FINAIS}

O aprendizado de um idioma estrangeiro é muito importante em um mundo extremamente globalizado em que vivemos, visto que podemos acessar uma grande quantidade de informações, de maneira fácil e rápida de todos os locais, tornando-se cada vez mais abrangente o acesso ao conhecimento. Sendo somente necessário aprender os idiomas em questão.

Os integrantes do Programa de Educação Tutorial (PET) Engenharia Civil do CEFET-MG campus Curvelo, têm uma grande presença na produção de conteúdo científico, com isso é imprescindível que os mesmos tenham acesso a essa grande biblioteca mundial a fim de melhorar o desenvolvimento de suas pesquisas, e consequentemente contribuir para o desenvolvimento da engenharia civil.

O curso PET English conseguiu atender todas as expectativas propostas quanto a sua ministração, conseguindo passar na essência o que foi proposto, de um modo simples, 
dinâmico e com a contribuição de todos os participantes, com isso o método se tornou uma alternativa eficaz de se aprender o idioma.

\section{Agradecimentos}

Agradecemos ao Grupo PET de Engenharia Civil por nos propiciar um grande aprendizado, e a oportunidade de crescer academicamente. Agradecemos também as nossas tutoras por nos ensinar e orientar. E por fim, ao CEFET-MG por nos dar a oportunidade de estudar e ter uma formação.

\section{REFERÊNCIAS}

ARAÚJO, Letícia Maria Martins et al . Ensino da Língua Inglesa: contribuições da fonética, fonologia e do processamento auditivo. Pró-Fono R. Atual. Cient., Barueri , v. 22, n. 3, p. 183-188, Sept. $2010 . \quad$ Disponível em: http://www.scielo.br/scielo.php?script=sci_arttext\&pid=S010456872010000300005\&lng=en\&nrm=iso. Acesso em: 20 Apr. 2021.

BARROS,R. S.; ABRANCHES,S.P. Duolingo: a utilização da plataforma como ferramenta didática para $o$ processo de ensino e aprendizagem em línguas estrangeiras. Revista Cadernos de Estudos e Pesquisa na Educação Básica, Recife, v.4, n.1, p.162-172,2018. CAp UFPE.

Busuu. 10 motivos para aprender inglês. 2021. Disponível em: https://www.busuu.com/pt/languages/reasons-to-learn-english. Acesso em: 17 abr. 2021.

CULTURA INGLESA. Entenda Por Que O Inglês É O Idioma Mais Importante Do Mundo. 2020. Disponível em: https://blog.culturainglesa.com.br/ingles/. Acesso em: 17 abr. 2021.

DUOLINGO. Como posso usar o Duolingo?. Disponível em: https://support.duolingo.com/hc/pt-br/articles/360035932192-Como-posso-usar-oDuolingo-. Acesso em: 20 abr. 2021.

DUOLINGO. Perguntas frequentes sobre o Duolingo para Escolas. Disponível em: https://schools.duolingo.com/help. Acesso em: 20 abr. 2021.

DUOLINGO. Quem Somos?. Disponível em: https://pt.duolingo.com/approach. Acesso em: 20 abr. 2021.

DUOLINGO. O que é o Duolingo?. Disponível em: https://support.duolingo.com/hc/ptbr/articles/204829090-O-que-\%C3\%A9-o-Duolingo-. Acesso em: 20 abr. 2021.

EDITOR, Insider. Conheça 5 dos melhores aplicativos para aprender idiomas, 29 jan. 2021. Disponível em: https://www.insiderstore.com.br/blog/conheca-5-dos-melhoresaplicativos-para-aprender-idiomas/. Acesso em: 20 abr. 2021.

FRAGOSO, Carina. Sou péssimo em inglês: tudo que você precisa saber para alavancar de vez o seu aprendizado. - 1. ed. - Rio de Janeiro: HarperCollins, 2018. 
Go Natural English Blog. HOW MUCH TIME DOES IT TAKE TO SPEAK ENGLISH FLUENTLY?. Austin - TX - USA. 2021. Disponível em: https://www.gonaturalenglish.com/how-much-time-tofluency/\#: :text=Each\%20of\%20these\%20levels\%20takes,familiarity\%20with\%20learning \%20other\%20languages. Acesso em: 17 abr. 2021.

KO Y, Wang M, Kim SY. Bilingual Reading of Compound Words. J. Psycholinguist. Res. Publishing on line. 2010 jul

LEMHÖFER $\mathrm{K}$, Schrefers $\mathrm{H}$, Hanique I. Native languagem effects in learining secondlanguage grammatical gender: a training study. Acta Psychol. Ahead of print. 2010 jun.

LIMA, Denilson de. Inglês na ponta da língua: método inovador para melhorar seu

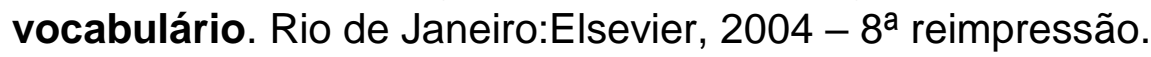

SILVA, Sérgio Manoel da. FRANÇA, Lucineide Pires da Silva. SILVA, Maria Bizerra da. Importância da tecnologia: No ensino da Língua Estrangeira e Inglesa. Revista Científica Multidisciplinar Núcleo do Conhecimento. Ano 05, Ed. 04, Vol. 01, pp. 174-184. Abril de 2020. ISSN: 2448-0959, Link de acesso: https://www.nucleodoconhecimento.com.br/educacao/importancia-da-tecnologia. Acesso em 24 de abril de 2021.

SILVA, F. M. $O$ ensino de língua inglesa sob uma perspectiva intercultural: caminhos e desafios. Trabalhos em Linguística Aplicada. Campinas, SP, v. 58, n. 1, p. 158-176, 2019.

Disponível

em: https://periodicos.sbu.unicamp.br/ojs/index.php/tla/article/view/8654189. Acesso em: 20 abr. 2021.

SOARES, K. R. B.; LIMA, S. C. O uso do duolingo no ensino de língua inglesa em curso técnico de nível médio integrado. Revista LínguaTec, Instituto Federal de Educação, Ciência e Tecnologia do Rio Grande do Sul, Bento Gonçalves v. 3, n. 1, p. 158-170, jun. 2019.

S. (Orgs.). Diversidade cultural e ensino de língua estrangeira. Campinas, SP: Pontes Editores, p. 97-110.

\section{PET ENGLISH: IMPLEMENTATION OF THE TEACHING AND LEARNING PROCESS IN FOREING LANGUAGES IN THE PET GROUP OF CIVIL ENGINEERING CEFET - MG.}

Abstract: Learning a foreign language is a very important step in opening up a range of opportunities, whether in personal, professional or academic life. It is also essential to consider what your goals are and have them very clear, so that you do not lose or give up halfway through learning this new language, as it is a long journey. Aiming that the members of the Tutorial Education Program (PET) Civil Engineering of the CEFET-MG Curvelo campus have a very intense scientific research production activity, the idea arose of offering a preparatory English course so that they have the possibility of having contact with a wider range of bibliographic references for the production of articles, based on language learning. 
In an initial survey it was found that all participants had no proficiency in a foreign language and had a very basic level in English. At the end of the course, all participants reported that they had a good experience with the course, and that they will possibly continue to study later.

Keywords: English. Teaching. Apprenticeship. Duolingo 